\title{
Higher education teachers' experiences with learning analytics in relation to student retention
}

\author{
Deborah West \\ Charles Darwin University \\ Henk Huijser \\ Xi'an Jiaotong Liverpool University \\ Batchelor Institute of Indigenous Tertiary Education \\ David Heath \\ Charles Darwin University
}

Alf Lizzio

Griffith University

Danny Toohey

Murdoch University

Carol Miles

University of Newcastle

Bill Searle

Charles Darwin University

Jurg Bronnimann

Batchelor Institute of Indigenous Tertiary Education

\begin{abstract}
This paper presents findings from a study of Australian and New Zealand academics $(n=$ 276) who teach tertiary education students. The study aimed to explore participants' early experiences of learning analytics in a higher education milieu where data analytics is gaining increasing prominence. Broadly speaking participants were asked about: (1) their teaching context; (2) their current student retention activities; (3) their involvement in, and aspirations for, learning analytics use; and (4) their relationship with their institution around learning analytics. The sampled teaching staff broadly indicated a high level of interest but limited level of substantive involvement in learning analytics projects and capacity building activities. Overall, the intention is to present a critical set of voices that assist in identifying and understanding key issues and draw connections to the broader work being done in the field.
\end{abstract}

\section{Introduction}

This paper reports on one component of an Australian Government Office for Learning and Teaching (OLT) funded project entitled Learning analytics: Assisting universities with student retention. Carried out over the period from April 2014 to November 2015 this mixed-method study investigated the factors that impact on the implementation of learning analytics for student retention purposes.

At the commencement of the project in July and August 2014, a survey of higher education institutions ( $n$ = 24) found that typically institutions were focused on exploring, planning, and piloting different tools and applications designed to improve their analytics capacity (West, 2015; West, et al., 2016). Though analytics was the subject of much attention in institutions, what was less clear was the extent to which the focus of analytics would be on the business dimensions of human resources, marketing, performance management, and workload allocation, or whether the analytics focus would be more the educational dimensions of learning environments, curriculum design, pedagogical intent, and student experience, for example. Although these two broad dimensions are not necessarily dichotomous, the initial institution level survey 
suggested that integrating human resources, finance, research, and marketing systems into some kind of data warehouse tended to be one of the more advanced strategic priorities within surveyed institutions at the time (West, 2015).

The institution level survey provided some useful baseline data around institutional decision making and progress with learning analytics, but the ways that teaching staff were influencing the direction for learning analytics or participating in learning analytics pilots and projects remained unclear. The next phase of the project involved the deployment of an academic level survey, which aimed to further knowledge about the experiences of teaching staff and other academics with learning analytics, explore their aspirations, and elicit their views on key issues identified in the literature. Data from the academic level survey is the primary focus of this paper.

\section{Background}

\section{Learning analytics}

The rise of big data, growth in online learning, and changing politics around higher education are driving interest in learning analytics (Ferguson, 2012). Ochoa, Suthers, Verbert, and Duval (2014; p. 5) observe that "learning analytics is a new, expanding field that grows at the confluence of learning technologies, educational research, and data science”, before indicating that learning analytics has the potential to solve two simple but challenging questions:

1. How do we measure the important characteristics of the learning process? and

2. How do we use those measurements to improve it?

Given the breadth of the above description it is perhaps unsurprising that previous research (Corrin, Kennedy, \& Mulder, 2013) found that understandings of learning analytics vary amongst academic staff. Further, the questions listed by Ochoa and colleagues do not seem too different to those that have existed in higher education for many years. However, Ferguson (2012) makes the point that learning analytics typically includes a pair of assumptions around the utilisation of machine readable data and a focus on big data systems and techniques.

\section{Student retention}

The academic and non-academic factors that can influence retention are complex and varied (Nelson, Clarke, Stoodley, \& Creagh, 2014). Complicating matters are the relationships between retention, success, and engagement. Helpfully though, there are numerous relevant studies, including recent OLT (formerly the Australian Learning and Teaching Council [ALTC]) projects, on student retention (see Nelson et al., 2014; Willcoxson et al., 2011), alongside studies on learning analytics with some connection to student retention. Signals at Purdue University (Arnold \& Pistilli, 2012) is a noted example, though more are emerging (e.g. Harrison, Villano, Lynch, \& Chen, 2015).

Thinking more holistically, Tinto (2009) suggests that to be serious about student retention, universities need to recognise that the roots of student attrition lie not only in students and the situations they face, but also in the character of the educational settings in which students are asked to learn. If one goes back to the definition adopted by the Society for Learning Analytics Research (SoLAR), which articulates learning analytics as "the measurement, collection, analysis and reporting of data about learners and their contexts, for purposes of understanding and optimizing learning and the environments in which it occurs" (Siemans \& Long, 2011, p. 34), it becomes clear that student retention (and success and engagement) have a natural affinity with learning analytics.

Tinto (2009) has articulated four conditions of student success: expectations, support, feedback, and involvement (or engagement), and Nelson et al. (2014) take this idea further and add more detail in their Student Engagement Success and Retention Maturity Model (SESR-MM) that includes the following categories:

1. learning - assessment, curricula, teaching practices, pedagogical styles

2. supporting - information, services, resources, people rich advice, advocacy and peer support 
3. belonging - interaction, inclusive activities, identity development/formation opportunities

4. integrating - academic literacies, personal literacies

5. resourcing - staff development, evidence base, communication, learning environments

Both Tinto's four conditions, and especially Nelson et al.'s categories are potentially measurable, which is where learning analytics becomes particularly relevant.

\section{Linking teaching staff to learning analytics and retention}

Corrin et al. (2013) reported on findings from a focus group study featuring 29 staff associated with teaching and learning at one Australian institution. A variety of educational problems, situations, and potential ideas were raised by the participants in their study. These fell into five broad categories:

1. student performance,

2. student engagement,

3. the learning experience,

4. quality of teaching and the curriculum, and

5. administrative functions associated with teaching.

These few studies alone illustrate that sizeable variation exists with respect to how learning analytics might be applied to issues like student retention. With this in mind, the intention of this study was to both incorporate the concepts in these studies into the research instruments and also consider how participant responses to open-ended questions fit or did not fit with these typologies.

\section{Aim}

As learning analytics is multi-disciplinary, multi-method, and multi-level in application, and this study was conducted at a time when participant knowledge was difficult to predict, the research questions are necessarily broad in scope. They are:

1. What variety exists in the online environments where teaching takes place?

2. What involvement do teaching staff currently have in using data to respond to retention issues?

3. In which learning analytics related activities have teaching staff been involved?

4. In which retention applications of learning analytics are participants most interested in?

5. How are institutions supporting learning analytics use amongst teaching staff?

\section{Method}

\section{Sampling procedure}

The survey employed a purposive, snowball sampling strategy to recruit self-selecting individuals. Given the sizeable pool of potential participants, voluntary nature of the research, and presence of other higher education focused projects also seeking participants, obtaining a high response rate was expected to be a significant challenge and this was reflected in the data collection phase. The research team did take a number of steps to try to minimise sample bias, and information about participant recruitment and sample demographics will be presented to support evaluation of the representativeness of the sample.

\section{Participant recruitment}

Invitations were circulated via three main avenues:

1. Project team networks: The project team, reference group and evaluation team were comprised mainly of senior academics so the decision was taken to use their networks with other institutions leaders to facilitate as broad a distribution as the voluntary nature of the project would allow. Although the ideal scenario would have been universal distribution by institutions, in reality the approaches to senior institutional contacts resulted in varied forms of distribution:

- $\quad$ distribution of invitations via a specific learning and teaching mailing list;

- $\quad$ placement of information in a broader newsletter; 
- $\quad$ forwarding to department heads for discretionary distribution;

- $\quad$ distribution of the survey invitation throughout the institution; and,

- $\quad$ declining to distribute information about the project.

Follow up confirmed that the invitation was circulated to staff in some capacity in at least 25 institutions. In most cases distribution was partial and in three cases it was institution-wide.

2. Professional interest groups: Information about the project was distributed through either meetings or the newsletters of the Higher Education Research and Development Society of Australasia, Universities Australia, Council of Australian Directors of Academic Development, Australasian Council on Open and Distance Education, and Council of Australian University Librarians.

3. Conferences and workshops: As is fairly typical, project team members attended conferences and conducted workshops as the project progressed, but to avoid a disproportionate number of learning analytics enthusiasts, participant recruitment via this avenue was intentionally incidental rather than proactive.

Table 1 presents data that shows how this overall approach led to response patterns indicative of wide distribution (e.g., one that is not stacked with many participants just from partner institutions).

Table 1

Survey completion information

\begin{tabular}{|l|l|}
\hline Minimum number of institutions with at least one participant & 21 \\
\hline Separate days where at least one survey was commenced & 47 \\
\hline First survey commenced & 2 September 2014 \\
\hline Last survey commenced & 13 November 2014 \\
\hline
\end{tabular}

\section{Demographics}

In total 401 people viewed the survey’s first question. Forty-eight people (12\%) who answered no questions or only demographic questions were excluded. Of the remaining 353 participants, 276 (78\%) answered yes to the question "Do you teach students?" This paper is concerned with those 276 respondents. Using this parameter allows issues specific to teaching staff to be identified and explored. Table 2 presents a summary of the sample demographics. 
Table 2

Frequency distribution of selected demographic data

\begin{tabular}{|c|c|c|c|}
\hline $\begin{array}{l}\text { Variable } \\
\text { ( } n \text { varies due to missing data) }\end{array}$ & Category & $\begin{array}{l}\text { Absolute } \\
\text { frequency }\end{array}$ & $\begin{array}{l}\text { Relative } \\
\text { frequency }\end{array}$ \\
\hline \multirow{2}{*}{$\begin{array}{l}\text { Location } \\
(n=274)\end{array}$} & Australia & 269 & $98 \%$ \\
\hline & New Zealand & 5 & $2 \%$ \\
\hline \multirow{7}{*}{$\begin{array}{l}\text { Primary work role } \\
(n=276)\end{array}$} & Teaching students & 185 & $67 \%$ \\
\hline & Learning support & 25 & $9 \%$ \\
\hline & Other & 24 & $9 \%$ \\
\hline & Research & 19 & $7 \%$ \\
\hline & Management/administration & 12 & $4 \%$ \\
\hline & Academic development & 7 & $3 \%$ \\
\hline & Student support & 4 & $1 \%$ \\
\hline \multirow{3}{*}{$\begin{array}{l}\text { LMS at institution } \\
(n=276)\end{array}$} & Blackboard & 175 & $63 \%$ \\
\hline & Moodle & 89 & $32 \%$ \\
\hline & Other & 12 & $4 \%$ \\
\hline \multirow{4}{*}{$\begin{array}{l}\text { Employment basis } \\
(n=275)\end{array}$} & Full time & 223 & $81 \%$ \\
\hline & Part time & 35 & $13 \%$ \\
\hline & Casual & 15 & $5 \%$ \\
\hline & Other & 2 & $1 \%$ \\
\hline \multirow{6}{*}{$\begin{array}{l}\text { Academic level } \\
(n=276)\end{array}$} & Lecturer & 115 & $42 \%$ \\
\hline & Senior Lecturer & 79 & $29 \%$ \\
\hline & Associate Professor & 28 & $10 \%$ \\
\hline & Associate Lecturer/Tutor & 24 & $9 \%$ \\
\hline & Professor & 18 & $7 \%$ \\
\hline & Other & 12 & $4 \%$ \\
\hline \multirow{5}{*}{$\begin{array}{l}\text { Length of employment in current } \\
\text { institution } \\
(n=251)\end{array}$} & Less than 1.5 years & 18 & $7 \%$ \\
\hline & $1.5-5$ years & 57 & $22 \%$ \\
\hline & $5-10$ years & 77 & $31 \%$ \\
\hline & 10- 20 years & 72 & $29 \%$ \\
\hline & More than 20 years & 27 & $11 \%$ \\
\hline \multirow{5}{*}{$\begin{array}{l}\text { Length of employment in higher } \\
\text { education sector } \\
(\mathrm{n}=269)\end{array}$} & Less than 1.5 years & 4 & $1 \%$ \\
\hline & $1.5-5$ years & 35 & $13 \%$ \\
\hline & $5-10$ years & 61 & $23 \%$ \\
\hline & 10- 20 years & 105 & $39 \%$ \\
\hline & More than 20 years & 64 & $24 \%$ \\
\hline \multirow{4}{*}{$\begin{array}{l}\text { Enrolment } \\
\text { taught } \\
(n=276)\end{array}$} & Internally enrolled students only & 144 & $52 \%$ \\
\hline & $\begin{array}{l}\text { A mix of internal and external } \\
\text { students }\end{array}$ & 105 & $38 \%$ \\
\hline & Externally enrolled students only & 14 & $5 \%$ \\
\hline & Other & 12 & $4 \%$ \\
\hline
\end{tabular}

In relation to primary work role the "other" response was 9\%. This group of responses did not expand much on the categories listed, rather most participants who put "other" did so to express a reluctance to identify a single role as "primary", with 18 people nominating a split between teaching and research.

\section{Materials and procedure}

The survey was a purpose designed online questionnaire, built and hosted at Qualtrics. It was accessed via a link which made responses anonymous. To alleviate risk of multiple completions by individuals the software allowed one survey attempt per computer/IP address. Participants could save and return to an incomplete survey. After 2 weeks with no access an in-progress attempt was automatically closed and placed with completed surveys. Ethics approval for the study was granted by the Charles Darwin University Human Research Ethics Committee. 


\section{Results}

\section{Question 1. What variety exists in the online environments where teaching takes place?}

The teaching environments chosen by academics have a range of implications for what is possible with learning analytics. Table 3 details results when participants were asked about their use of tools or utilities outside the LMS for teaching.

Table 3

Frequency distribution of online teaching activities of participants

\begin{tabular}{|c|c|c|c|}
\hline Variable & Category & $\begin{array}{c}\text { Absolute } \\
\text { Frequency }\end{array}$ & $\begin{array}{c}\text { Relative } \\
\text { Frequency }\end{array}$ \\
\hline \multirow{6}{*}{$\begin{array}{l}\text { Tools or } \\
\text { utilities } \\
\text { outside the } \\
\text { LMS used for } \\
\text { teaching } \\
(n=272)\end{array}$} & Does not use tools or utilities to teach outside the LMS* & 120 & $44 \%$ \\
\hline & Website hosted externally & 57 & $21 \%$ \\
\hline & Website hosted by their institution & 54 & $20 \%$ \\
\hline & Others & 53 & $20 \%$ \\
\hline & Social media applications & 51 & $19 \%$ \\
\hline & Mobile apps & 22 & $8 \%$ \\
\hline Teaching & Provision of access to learning materials & 89 & $63 \%$ \\
\hline activities & Assessment submission and feedback & 75 & $52 \%$ \\
\hline $\begin{array}{l}\text { conducted } \\
\text { outside the }\end{array}$ & $\begin{array}{l}\text { Learning focused interactions between lecturers and } \\
\text { students }\end{array}$ & 59 & $41 \%$ \\
\hline $\begin{array}{l}\text { LMS } \\
(n=156)^{* *}\end{array}$ & Learning focused interactions between students & 48 & $34 \%$ \\
\hline
\end{tabular}

Note. * denotes mutually exclusive response,

** not asked of 120 participants not teaching outside the LMS.

For the first variable in Table 3 there was space to list the applications for the "social media", "mobile apps" and "other" options. Social media applications included: Facebook (28), Twitter (14), YouTube (13), Yammer (3), Instagram (3), Pinterest (2), WordPress (2), Blackboard (2), and 10 singularly mentioned applications. In relation to mobile apps it was apparent that a distinction between social media and mobile apps was not necessarily mutually exclusive or clear. There were 20 different mobile apps mentioned. Finally, in the open "other" category there was a wide mix of responses. Coding into categories found these could be grouped into functions, which are, with examples from participant responses:

- $\quad$ productivity and content creation (e.g. multimedia software, Creative Cloud, iMovie);

- $\quad$ communication (email, Facebook, Skype);

- $\quad$ discipline dedicated learning resources and tools (many e.g. MathLab; Skritter);

- $\quad$ general content repositories housing learning materials (YouTube, Vimeo, Lynda);

- $\quad$ polling and quizzing (Respondus; PollEverywhere);

- document storage, sharing, and portfolio creation (e.g. Google Docs, Mahara);

- $\quad$ virtual and simulated learning environments ( e.g. Smart Sparrow); and,

- $\quad$ shared content creation spaces (e.g. Wikis and Blogs).

\section{Question 2: What retention related data are participants accessing and using?}

Methods of identifying at risk students

One way of exploring the uptake of learning analytics was to explore the types of data that participants were using to determine risk. Table 4 presents the frequency distribution of selected data sources used by participants. Please note that in the design and pilot phase it was unclear how certain participants would be so there a couple of different types of other categories to reflect this. The responses in the table are presented as they were in the survey instrument. In terms of the "other" option, class attendance and colleagues were the strongest responses. 
Table 4

Data sources considered when identifying at-risk students $(n=246)$

\begin{tabular}{|l|c|c|}
\hline Data source & $\begin{array}{c}\text { Absolute } \\
\text { Frequency }\end{array}$ & $\begin{array}{c}\text { Relative } \\
\text { Frequency }\end{array}$ \\
\hline $\begin{array}{l}\text { Students self-reporting that they are having issues that might affect their } \\
\text { retention }\end{array}$ & 146 & $59 \%$ \\
\hline LMS & 140 & $57 \%$ \\
\hline $\begin{array}{l}\text { Directly asking students if they are having any issues that might impact their } \\
\text { retention }\end{array}$ & 123 & $50 \%$ \\
\hline Student Information System & 59 & $24 \%$ \\
\hline Advised by specialist team that has their own retention monitoring processes & 45 & $18 \%$ \\
\hline Learning Support & 38 & $15 \%$ \\
\hline Student Support & 33 & $13 \%$ \\
\hline Does not take action to identify students with retention related risks* & 24 & $10 \%$ \\
\hline Consults data from other sources & 23 & $9 \%$ \\
\hline Teaching tools or utilities outside the LMS & 15 & $6 \%$ \\
\hline Consults data from other source/s but is not sure what they are called & 9 & $4 \%$ \\
\hline Library & 5 & $2 \%$ \\
\hline
\end{tabular}

Note. * denotes mutually exclusive response

Figure 1 shows a frequency distribution of participants' use of selected indicators to identify at-risk students in relation to retention. Notable here is a trend toward indicators that relate to actual performance than more predictive indicators often collected as part of student enrolment. As with the previous table, class attendance was also the most common response where participants were provided with space to put "others".

Task completion

Attainment of certain grades

LMS access patterns (e.g. logging in)

Use of communication tools (e.g...

Repeat student status

English proficiency

Materials or resources access..

Time spent in LMS

International student status

Academic pathway - basis for entry

Home language

Aboriginal and Torres Strait..

Socio-economic status

First in family to enrol in Higher..

Birth country

Not sure*
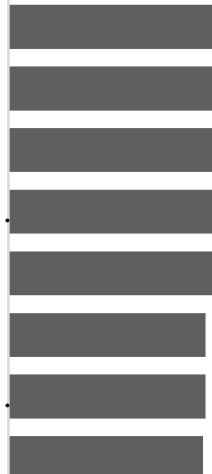

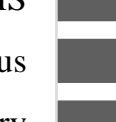



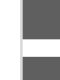


Involvement in responding to at-risk students

Participants were asked whether they had a systematic response when students met identified risk thresholds. A total of 103 participants had a systematic response, of which 24 (23\%) indicated it applied to all thresholds and 79 (77\%) indicated it applied to some thresholds only. These 103 participants were asked about the elements that comprised that response. Overwhelmingly, the most common responses were manually conducted (e.g., manual emails, telephone calls, offers of consultation, manual referrals to support services). The primary automated methods (emails, automated referrals, or those in the "other” category) all had a frequency where $n<15$.

\section{Question 3: In which learning analytics related activities have teaching staff been involved?}

The study also investigated participation in learning analytics activities. Results focus on the frequency of learning analytics discussions that teaching staff are involved in and the involvement of teaching staff in a more diverse selection of analytics activities.

\section{Learning analytics discussion involvement}

Figure 2 explores how often the teachers sampled discussed learning analytics with colleagues in different roles. For example, the series on the right hand side represents how often the teaching staff sampled discussed learning analytics with institutional management. Higher bars on the left of each series indicate more frequent discussion.

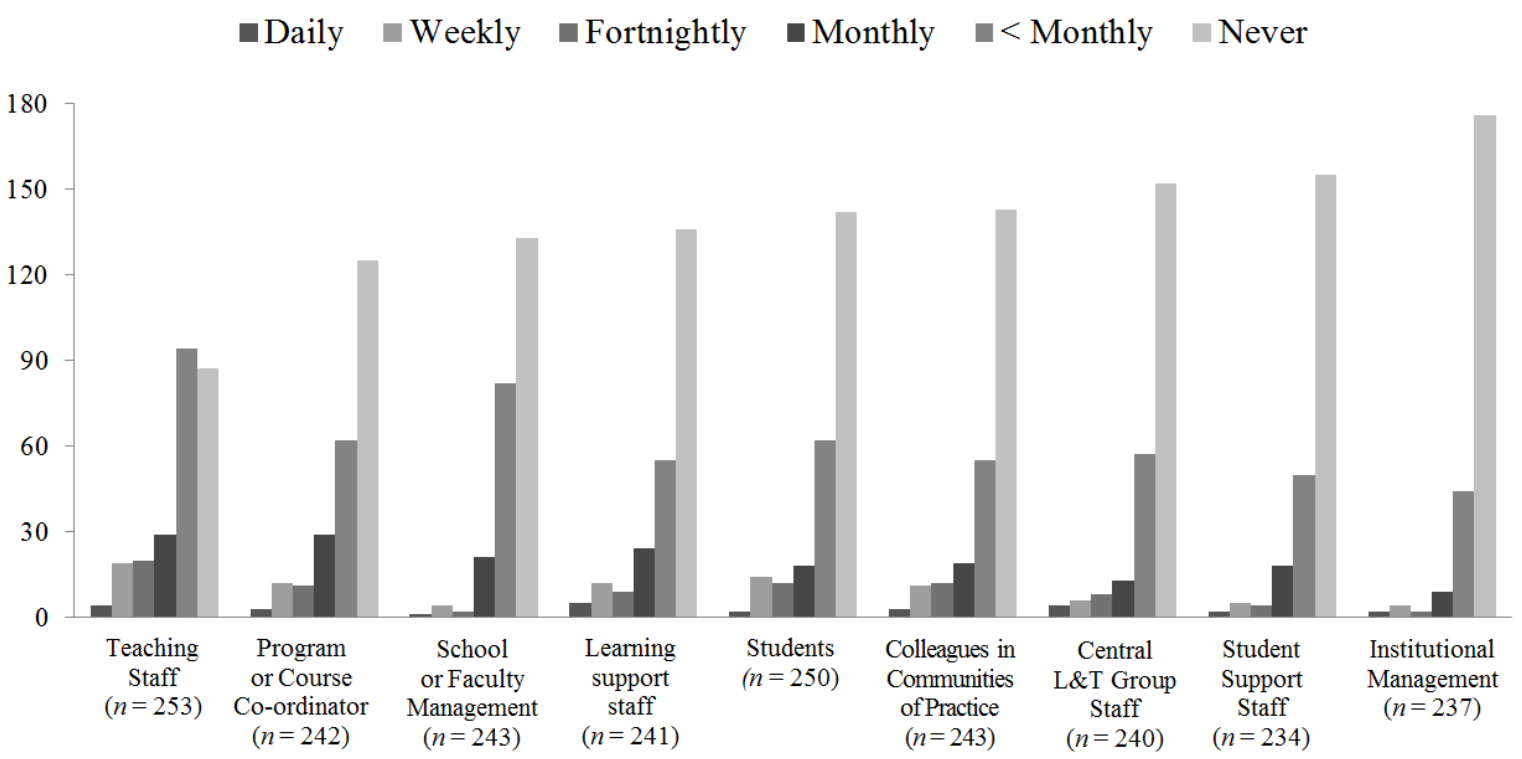

Figure 2. Frequency of learning analytics discussion with selected groups ( $n$ varies by variable)

Learning analytics activity involvement

Participants were also asked about whether they had been involved in a selection of learning analytics related activities. Table 5 presents the results. 
Table 5

Frequency distribution of involvement in selected learning analytics activities $(n=276)$

\begin{tabular}{|l|r|r|}
\hline Learning analytics related activity & $\begin{array}{r}\text { Absolute } \\
\text { Frequency }\end{array}$ & $\begin{array}{l}\text { Relative } \\
\text { Frequency }\end{array}$ \\
\hline None of the listed choices* & 108 & $40 \%$ \\
Using learning analytics to help with analysis and decision making & 101 & $37 \%$ \\
Reading about learning analytics for their own professional development & 100 & $37 \%$ \\
Advocating for the use of learning analytics to colleagues (informal or formal) & 70 & $26 \%$ \\
Attending conferences/ training specifically to learn about learning analytics & 56 & $21 \%$ \\
Conducting formal research and/or publishing work on the topic of learning & 26 & $10 \%$ \\
analytics & 24 & $9 \%$ \\
Being part of the group that is leading learning analytics at their institution & 9 & $3 \%$ \\
Delivering training on the use of learning analytics & \\
\hline
\end{tabular}

Note. *denotes mutually exclusive response

\section{Question 4: In which retention applications of learning analytics are participants interested?}

The survey sought to explore which broad retention related applications of learning analytics participants were most interested in. Participants were asked about their level of interest in nine selected applications with their responses displayed in Figure 3. Longer bars at the top of each series indicate higher interest levels.

\section{$\square$ A lot of interest $\quad \square$ A little interest $\quad$ No Interest}



Figure 3. Participant levels of interest in selected potential applications of learning analytics ( $n$ varies)

In interpreting the results readers need to be mindful of two things. First, participants were able to select "not sure" but this is not displayed to avoid disrupting the visual flow of the chart. The "not sure" option accounted for between $4 \%$ and $10 \%$ of responses for each application. Additionally, due to missing data, $n$ varied between 247 and 252 across the applications. 


\section{Question 5: How are institutions supporting learning analytics use amongst teaching staff?}

Subjective perceptions of needs being met

Participants were asked about the extent to which they felt the institution met their needs in relation to selected institutional provisions around learning analytics. Figure 4 shows participant responses when asked to rate their institution on seven indicators. Due to missing data, $n$ varied between 230 and 232 across the different response options in relation to institutions meeting participants’ perceived needs.

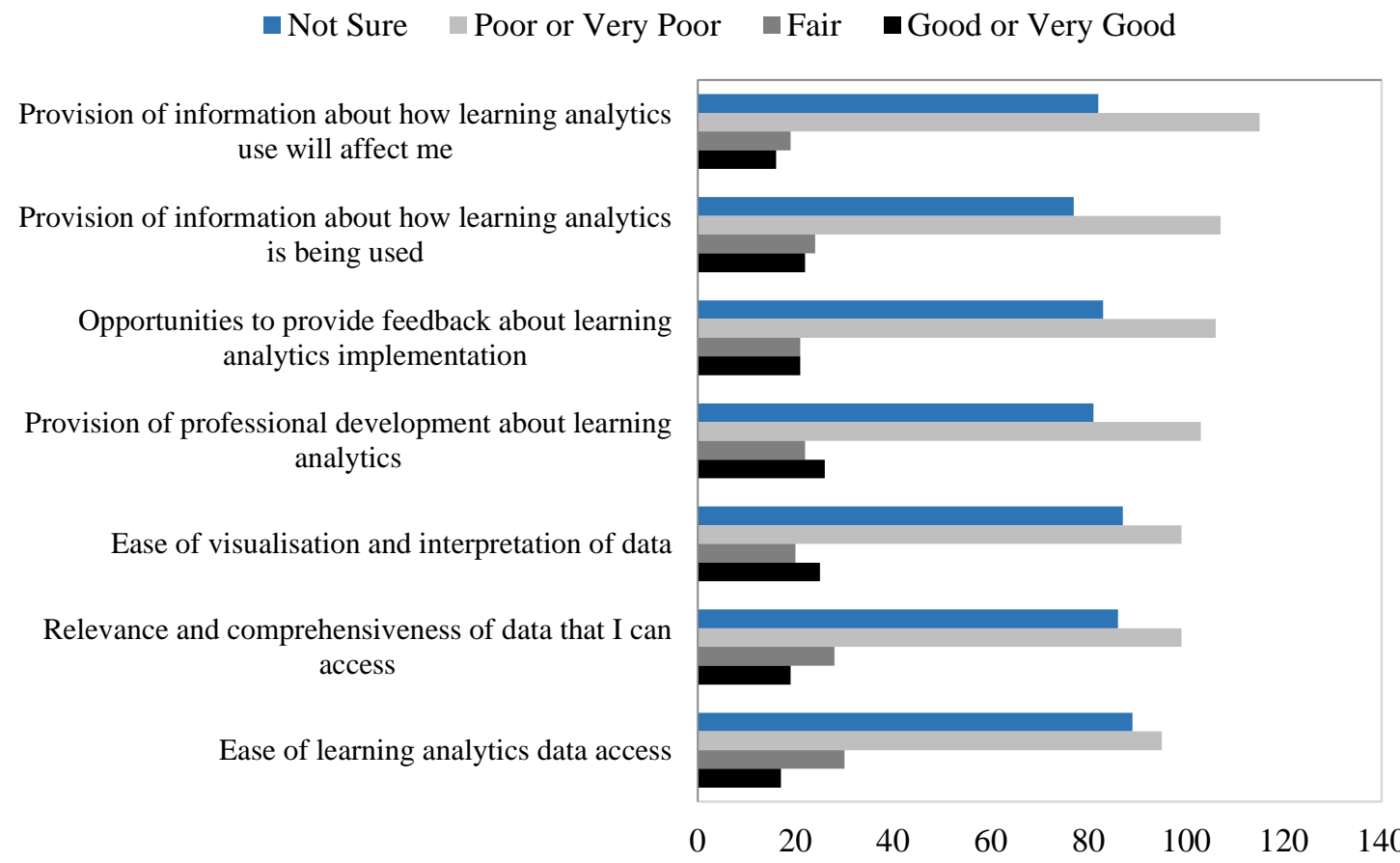

Figure 4. Rating of institution at meeting participant needs and expectations in selected areas ( $n$ varies)

\section{Professional development and training}

Participants were also asked whether they have attended or would attend training on five different topics: (1) introduction to learning analytics concepts and applications; (2) overview of institutional plan around learning analytics; (3) accessing data; (4) interpreting data; and, (5) responding to data. Results can be summarised into two key points. Firstly, none of the five types of training had been attended by more than $15 \%$ of participants. Secondly, participants were interested in training. Each of the five training topics had somewhere between $83 \%$ and $86 \%$ of participants indicating they have attended, or (more commonly) would attend, training on that topic.

\section{Discussion and conclusions}

Prior to delving into some of the key discussion points to emerge from the data, some limitations will be considered. Firstly, the sample size means that the external validity of the data is quite limited, though the authors have taken steps to carefully describe the sampling process and demographics. Secondly, the sample size also impacted on the statistical power and the end result is a largely descriptive and exploratory survey. However, some contentions are made about the value of the study in the context of these limitations:

1. The study illustrates some issues that are important even if they are not universal;

2. The mixed-method design means that academic level survey data can be connected to other project data (e.g., West, 2015) in very specific ways (e.g., contradictions and tensions between institutional direction and teachers priorities can be considered using the different data sets);

3. Whilst this project was taking place other work was occurring (e.g., a UniSA led OLT project Colvin et al., 2016) which can help expand the breadth and range of understanding; and, 
4. At this point in time, sector level research is likely to generate further questions rather than solutions to specific problems because to some extent the key challenges and issues are still being delineated.

A key message, consistently reinforced, was that participants generally expressed a high level of interest in learning analytics, but their participation in learning analytics activities was limited, particularly in a collaborative way. Although 37\% of participants reported using analytics to help with making decisions, very few participants engaged in frequent (e.g., weekly or fortnightly) discussion with colleagues, especially outside of other teaching staff. As learning analytics is seen as a field where collaborative use of different expertise (e.g., data science, pedagogy, discipline knowledge) is important (Ochoa et al., 2014), a lack of communication represents a barrier to progress. A similar conclusion can be drawn from the data about training, in which roughly $85 \%$ of participants reported interest in attending analytics training, but very few had attended.

What might be stopping teaching staff pursuing learning analytics in line with their reported interests? In addition to the data reported in the results section, the survey featured a number of open ended qualitative questions discussed elsewhere (West, 2015), however one of these questions bears mentioning here. When participants were asked what they needed to pursue their learning analytics goals there were four dominant responses - clarity, access, training and time, concisely connected by one participant who suggested: "Tell me what data is available, give me access to it, give me the time to use it and give me guidance in using it". Even extensive discussion would likely be insufficient to explore all the ways in which these needs might be met, however such views do highlight two related tensions in the learning analytics space:

1. distributed versus centralised locations as the source analytics of initiation and innovation; and

2. homogeneity versus heterogeneity of analytics focus (i.e. how universal are the problems within an institutional context that analytics might be used to address?).

Learning analytics has been a hot topic over the past couple of years and significant discussion, particularly at the institutional level, has been about integrating major data systems, with a view to large projects applying predictive analytic and other business intelligence techniques for example (West, 2015). Given the often centralised management and focus of these projects teaching staff might be aware of their presence, but not been provided with enough information to form a coherent understanding of what their role might be, or how the analytic tools, techniques and problem questions of interest to them might differ from those being used centrally by institutional, managers leaders and central departments. There are potentially a number of reasons for this:

- institutional leaders see their analytics as largely about tools for institutional leaders and managers;

- institutional leaders do see a role for teaching staff but are not yet sure what that might be;

- institutional leaders envision a role for teaching staff, but promoting this a future priority;

- institutional leaders are not necessarily aware that teachers are interested in learning analytics; and/or,

- institutional leaders view the individual problems or questions that teachers might address with analytics as distinctly heterogeneous and see analytics initiatives as best driven at distributed or localised contexts.

Perhaps lending weight to the final suggestion is that when participants were asked about their teaching activities outside the LMS, there was a wide array of tools and applications utilised. Whilst academics may have originally selected these tools based on their fit to identified learning requirements, many of these tools have embedded analytics functionality (e.g., Iconosquare for Instagram, Google Analytics) that can be used out of the box, or as learning analytics researchers (e.g., Kitto, Cross, Waters, \& Lupton, 2015) are increasingly demonstrating, customised to higher education learning settings using open source tools.

The key question about who makes decisions about what to pursue with regards to learning analytics is an important one and one that is liable to vary significantly from institution to institution. Some institutions have a clear preference (often supported by policy) that academic staff use the LMS, whereas others allow much more discretion (West, 2015). Similarly, some institutions may be focused on developing learning analytics reports and dashboards for use across the institution, whereas others may see the role of teaching staff, program coordinators and/or educational developers as working together to select and use teaching 
tools and technologies that meet their unique data needs.

Ultimately, one of the overriding themes across the entire project was about the challenge of dealing with the variety of choices that exists in the new era of analytics. Clearly the choices about what to explore and adopt can be at once dizzyingly complicated and numerous, yet full of possibility. This study represents an initial contribution in the context of a broader community where much is being done to collaboratively build capacity around learning analytics and support people across all levels of the sector to better understand potential uses.

\section{Further information}

More information about the project, including presentations and resources (e.g. framework of factors impacting on institution level learning analytics implementation and accompanying set of discussion questions) from the National Forum are available on the project website at www.letstalklearninganalytics.edu.au

\section{Acknowledgements}

Support for this publication has been provided by the Australian Government Office for Learning and Teaching. The views expressed in this paper do not necessarily reflect the views of the Australian Government Office for Learning and Teaching.

\section{References}

Arnold, K., \& Pistilli, M. (2012). Course signals at Purdue: Using learning analytics to increase student success. Proceedings of the 2nd International Conference on Learning Analytics and Knowledge (LAK '12), Vancouver, British Columbia, Canada, (pp. 67-270). http://dx.doi.org/10.1145/2330601.2330666

Colvin, C., Rogers, T., Wade, A., Dawson, S., Gasevic, D., Buckingham Shum, S., ... \& Fisher, J. (2016). Student retention and learning analytics: A snapshot of current Australian practices and a framework for advancement. Canberra, ACT: Australian Government Office for Learning and Teaching. Retrieved from http://www.olt.gov.au/project-student-retention-and-learning-analytics-snapshotcurrent-australian-practices-and-framework

Corrin, L., Kennedy, G., \& Mulder, R. (2013). Enhancing learning analytics through understanding the needs of teachers. In Electric Dreams. Proceedings ascilite Sydney 2013 (pp. 201-205). Retrieved from http://www.ascilite.org/conferences/sydney13/program/papers/Corrin.pdf

Ferguson, R., (2012). Learning analytics: Drivers, developments and challenges. International Journal of Technology Enhanced Learning, 4(5/6), 304-317. http://dx.doi.org/10.1504/IJTEL.2012.051816

Harrison, S., Villano, R., Lynch, G., \& Chen, G. (2015). Likelihood analysis of student enrollment outcomes using learning environment variables: A case study approach. Proceedings of the 5th International Conference on Learning Analytics and Knowledge (LAK '15), Poughkeepsie, NY, 141145. http://dx.doi.org/10.1145/2723576.2723621

Kitto, K., Cross, S., Waters, Z., \& Lupton, M. (2015). Learning analytics beyond the LMS: The connected learning analytics toolkit. Proceedings of the 5th International Conference on Learning Analytics and Knowledge (LAK '15), Poughkeepsie, NY, 11-15. http://dx.doi.org/10.1145/2723576.2723627

Nelson, K., Clarke, J., Stoodley, I., \& Creagh, T. (2014). Establishing a framework for transforming student engagement, success and retention in higher education institutions. Final Report 2014, Canberra, Australia: Australian Government Office for Learning \& Teaching. Retrieved from http://studentengagementmaturitymodel.net/wpcontent/uploads/2013/07/ID11_2056_Nelson_Report_2014-1-1.pdf

Ochoa, X., Suthers, D., Verbert, K., \& Duval, E. (2014). Analysis and reflections on the third Learning Analytics and Knowledge Conference (LAK 2013). Journal of Learning Analytics, 1(2), 5-22. Retrieved from: http://epress.lib.uts.edu.au/journals/index.php/JLA/article/view/4080

Siemens, G. \& Long, P. (2011). Penetrating the Fog: Analytics in learning and education. EDUCAUSE Review, 46(4) July/August. Retrieved from http://www.educause.edu/ero/article/penetrating-foganalytics-learning-and-education 
Tinto, V. (2009). Taking student retention seriously: Rethinking the first year of university. ALTC FYE Curriculum Design Symposium, Queensland University of Technology, Brisbane, Australia. pp. 1-10. Retrieved from http://www.fyecd2009.qut.edu.au/resources/SPE_VincentTinto_5Feb09.pdf

West, D. (2015). Method and findings. Proceedings of Let's Talk Learning Analytics. The National Forum for the Learning Analytics: Assisting Universities with Student Retention project. Griffith University, Queensland, Australia. pp. Retrieved from http://www.letstalklearninganalytics.edu.au/wp-content/uploads/2015/05/Findings-PresentationFinal.pdf

West, D., Huijser, H., Lizzio, A., Toohey, D., Miles, C., Searle, B., \& Bronnimann, J. (2016). Learning analytics: Assisting universities with student retention. Final Report (Part 1), Canberra, ACT: Australian Government Office for Learning and Teaching. Retrieved from http://www.olt.gov.au/resource-library?text=Learning+Analytics

Willcoxson, L., Manning, M., Hibbins, R., Joy, S., Thomas, J., Girardi, A., ... Lynch, B. (2011). The whole of university experience: Retention, attrition, learning and personal support interventions during undergraduate business studies. Surrey Hills, NSW: Australian Learning and Teaching Council. Retrieved from http://eprints.usq.edu.au/20138/

Corresponding author: Deborah West, deborah.west@cdu.edu.au

Australasian Journal of Educational Technology (c) 2016.

Please cite as: West, D., Huijser, H., Heath, D., Lizzio, A., Toohey, D., Miles, C., Searle, B., \& Bronnimann, J. (2016). Higher education teachers' experiences with learning analytics in relation to student retention. Australasian Journal of Educational Technology, 32(5), 48-60.

http://dx.doi.org/10.14742/ajet.3435 